\title{
MEMÓRIAS DE FORMAÇÃO E DOCÊNCIA DE UMA PROFESSORA DO INTERIOR DE MATO GROSSO DO SUL
}

\author{
Giseli Tavares de Souza Rodrigues iD1 e Luciene Cléa da Silva (D)
}

\section{Resumo}

Este trabalho tem como finalidade analisar as memórias de formação e docência de uma professora que atuou na carreira docente por 38 anos, residente no estado de Mato Grosso do Sul, bem como entender as relações de interdependências estabelecidas durante sua trajetória, e como essas relações influenciaram ou não na constituição de sua profissão. O texto contou com as contribuições metodológicas da História Oral Temática, com a utilização de entrevista como técnica de abordagem. A discussão teórica dialoga com Norbert Elias, a partir dos conceitos de figurações e redes de interdependências, além de ancorar-se em outros autores. Os dados elencados no estudo colaboram com a escrita da História da Educação, discussões sobre a profissão, memórias e trajetórias docentes no interior do Estado, considerando que pesquisas no município de Naviraí/MS são recentes, por isso a necessidade de ampliar as discussões sobre a temática. $E$ nos permitiu perceber também que as relações estabelecidas nas redes de interdependências que os indivíduos passam ou pertencem ao longo da vida influenciam em suas escolhas pessoais e profissionais. Tais escolhas remodelam a maneira de ser, e fazer do professor levando-o a se constituir na profissão docente, por meio das experiências que, esse, vai construindo ao longo de seu percurso profissional.

Palavras-chave: História da educação; Trajetória docente; Norbert Elias; Redes de interdependências.

\section{TRAINING AND TEACHING MEMORIES OF A TEACHER IN THE INTERIOR OF MATO GROSSO DO SUL}

\begin{abstract}
This work aims to analyze the memories of training and teaching of a teacher who worked in the teaching career for 38 years, resident in the state of Mato Grosso do Sul, as well as to understand the interdependent relationships established during her trajectory, and how these relationships influenced or not in the constitution of your profession. The text counted on the methodological contributions of Thematic Oral History, with the use of an interview as an approach technique. The theoretical discussion dialogues with Norbert Elias,
\end{abstract}

${ }^{1}$ Doutoranda em Educação pela Universidade Federal da Grande Dourados (UFGD).

${ }^{2}$ Doutora em Educação pela Universidade Federal da Grande Dourados (UFGD). Professora da Universidade Federal de Mato Grosso do Sul (UFMS) Campus de Ponta Porã (CPPP). 
based on the concepts of figurations and networks of interdependencies, in addition to being anchored in other authors. The data listed in the study collaborate with the writing of the History of Education, discussions about the profession, memories and teaching trajectories in the interior of the State, considering that research in the municipality of Naviraí/MS is recent, hence the need to expand discussions on the thematic. And it also allowed us to realize that the relationships established in the networks of interdependencies that individuals go through or belong to throughout their lives influence their personal and professional choices. Such choices reshape the teacher's way of being, and doing, leading him to constitute himself in the teaching profession, through the experiences that he builds along his professional path.

Keywords: History of Education; Teaching Path; Norbert Elias; Networks of Interdependence.

\section{Introdução}

Este trabalho é fruto dos resultados de uma pesquisa maior concluída no ano de 2019 que abordou a "História do Clube de Mães e as origens do atendimento à criança pequena em Naviraí/MS (1974 - 1990)", desenvolvida no programa de pós-graduação em educação da Faculdade de Educação da Universidade Federal da Grande Dourados - PPGEdu/UFGD, atrelada aos estudos desenvolvidos no Grupo de Pesquisa Educação e processo Civilizador - GPEPC, além das reflexões e pesquisas acerca da profissão e trajetórias docentes.

Assim, trazemos neste texto um recorte de entrevista realizada no ano de 2018 com uma professora aposentada, residente no município de Naviraí/MS, que teve uma trajetória de 38 anos na docência com crianças. O objetivo do mesmo consistiu em analisar as memórias de formação e docência dessa professora, bem como entender as relações de interdependências estabelecidas durante sua carreira docente e como essas relações influenciaram ou não na constituição de sua profissão.

A professora Marilda, nome real da participante do estudo, usado de acordo com o rigor ético da pesquisa científica possui formação em magistério e Pedagogia e durante seus anos de trabalho passou pela sala de aula, gestão e coordenação. Iniciou na docência em 1969 em Presidente Prudente/SP em turmas de $1^{a}$ a $4^{a}$ série do primeiro grau - nomenclatura usada na época atuação até 1976. Neste mesmo ano Marilda juntamente com sua família mudou para Naviraí/MS, local onde realizou toda a sua carreira docente. Ainda em 1976 começou a trabalhar em uma turma do curso de magistério em uma escola estadual de Naviraí, e logo foi convidada a dar aulas para crianças de $2^{a}$ série também. Posteriormente, parou de lecionar no curso de magistério e ficou trabalhando com crianças de pré-escola e $3^{a}$ série até o ano de 2007 , quando se aposentou.

Desta forma, buscamos identificar, a partir da história de vida e das memórias da professora entrevistada, as seguintes questões: Qual a sua história 
de vida e como chegou à docência? Qual a formação que obteve e como foi ser professora pelo período de 38 anos?

A história e memórias da docência de Marilda se firmam como objeto principal de análise deste artigo, por ser uma trajetória construída no interior de Mato Grosso do Sul, mais especificamente em Naviraí, apontado em pesquisas como a de Faria (2018), Montiel (2019) e Rodrigues (2019), como um lugar com pouca produção acadêmica na perspectiva da história da educação, memórias e trajetórias docentes. Diante disso, almejamos que este trabalho colabore com as discussões e novas inquietações colocando-as em movimento, somando com outras descobertas e compreensões sobre a formação, docência e o ser professor no viés da história da educação.

Para tanto, apontamos que o trabalho com memórias de professores nos permite identificar e estudar diversos aspectos que envolvem a trajetória profissional dos indivíduos, como tratar sobre a profissão docente implicando também em investigar a formação, a prática e experiências da docência e, as pessoais, entre outras questões, pois como coloca Nóvoa, "[...] é impossível separar o eu profissional do eu pessoal" (2000, p. 17), isso nos faz entender que além dos docentes serem profissionais, são sujeitos pessoais e sociais produtores e personagens principais de suas histórias. E "os 'casos' reais do ensino e da aprendizagem são seguimentos das "vidas feitas histórias" que vivemos como professores, e fazem parte da história do exercício da profissão" (PERETZ, 2000, p. 201).

Desta forma, acreditamos que as memórias dos acontecimentos vividos e experienciados durante a carreira docente de professores aposentados, ao serem dialogadas, podem fornecer informações imprescindíveis para a compreensão da constituição da profissão docente e, no caso das professoras, entender os seus papeis enquanto mulheres, esposas, mães e professoras. "Assim sendo, representam a consciência da prática e são dignas de rigorosa investigação" (PERETS, 2000, p. 213). A escrita das memórias docentes merece ser registrada, pelo fato de contar as histórias de indivíduos que construíram legados importantes, muitas vezes se encontram escondidos e necessitam ser contadas para o crescimento de outras pessoas e "[...] o único meio de salvar tais lembranças, é fixá-las por escrito em uma narrativa seguida, uma vez que as palavras e os pensamentos morrem, mas os escritos permanecem" (HALBWACHS, 1990, p. 80-81).

As vidas dos indivíduos/professores e suas experiências pessoais, sociais, culturais e profissionais são evidenciadas levando ao entendimento do quanto os acontecimentos que ocorrem ao longo de seu percurso podem marcar e moldar toda uma vida e uma carreira, influenciando a maneira pela qual o indivíduo/professor pensa e age, tanto na vida pessoal como na profissional. Desta forma, quando estudamos as memórias de professores, bem como as suas histórias de vida e quando eles relatam os fatos vividos, reproduzem a própria história, trazendo-a para o momento presente e isso "[...] faz de si autor e ator, na versão pela qual reconhece mais a si mesmo e a vida que, reflexionada nesse processo, traduz-se em experiência" (NEVES; FRISON, 2020, p. 3). 
No intuito de possibilitar a rememoração e constituição das histórias destes indivíduos/professores, trabalhamos com a História Oral Temática, que privilegia e está atrelada a um conteúdo exclusivo, proporcionando o testemunho dos indivíduos e a retomada de suas experiências de vida pessoal ou profissional. A "História Oral Temática aborda questões externas, objetivas, factuais, temáticas" (MEIHY, 1994, p. 57), objetiva ouvir fatos ocultos e dá oportunidade para o indivíduo falar sobre sua história, permitindo o contato direto do pesquisador com sua fonte de estudo.

Partimos dos pressupostos teóricos de Norbert Elias, o qual ensina que nas relações humanas, sociais e profissionais existe o que ele chama de figurações, que são compostas por grupos de indivíduos em espaços sociais como escola, academia, igreja, família, trabalho e entre outros (ELIAS, 2006). Compreendemos, a partir de Elias, que a sociedade não é nada além de indivíduos ligados e cada um possui um papel distinto a desempenhar em lugares figuracionais que ocupam. E por meio de múltiplas relações, nas figurações de pessoas, há um elo que os tornam conectados, e nessa direção aparece a interdependência que está ligada a:

[...] planos e ações, impulsos emocionais e racionais de pessoas isoladas constantemente se entrelaçam de modo amistoso ou hostil. [...] É essa ordem de impulsos e anelos humanos entrelaçados, essa ordem social, que determina o curso da mudança histórica, e que subjaz ao processo civilizador (ELIAS, 1993, p. 194).

Por meio das colocações do autor, entendemos que o rumo que a sociedade segue continuamente desde o início da civilização, passando por normas sociais, valores, organizações, perspectivas de vida em comum e finalidades de cada período pode ser chamado de processo civilizador. Isso mostra, sobretudo, que o passado, o presente e o futuro estão permeados por um movimento contínuo (ELIAS, 2001). Compreendemos, desta forma, que nesse movimento existem as trocas e as diversas figurações instituídas entre os pares/professores que podem também resultar em coisas, imóveis e nãomutáveis, porém, é notável que a sociedade se forma de relações entre indivíduos que se aproximam e se distanciam segundo os jogos de interesses e necessidades, pois "[...] somos nós próprios um ser entre os outros" (ELIAS, 2005, p. 13).

Assim, cremos na constituição da profissão docente como uma, "[...] construção social, realidade dinâmica e contingente, calcada em ações coletivas de atores sociais. Requer formação profissional para seu exercício: aquisição de habilidades e conhecimentos vinculados à atividade" (SANTOS, 2013, p. 30), por isso buscamos compreender como tais processos se fizeram presentes na trajetória da professora Marilda. 


\section{Procedimentos metodológicos: um caminho de dependência e interdependências}

Para desenvolver este trabalho respaldamo-nos na História Oral, a qual é entendida como "[...] um método de pesquisa (histórica, antropológica, sociológica etc.) que privilegia a realização de entrevista com pessoas que participaram de, ou testemunharam acontecimentos, conjunturas, visões de mundo" (ALBERTI, 2013, p. 24). Usamos a entrevista como técnica de coleta de dados, e por meio dela tornou-se possível o contato com as experiências e memórias da professora Marilda, as quais foram fundamentais para constituir todo o corpus documental deste trabalho. Seguimos todo o procedimento da abordagem metodológica da História Oral, como gravação, transcrição, textualização e procedimentos éticos de pesquisa.

Consideramos que as fontes orais podem revelar o inexprimível, aquilo que não poderia ser localizado se não fosse por meio delas. Porque carregam em si "[...] toda uma série de realidades que raramente aparecem nos documentos escritos, seja porque são consideradas "muito insignificantes" - é o mundo da cotidianidade - ou inconfessáveis, ou porque são impossíveis de transmitir pela escrita" (JOUTARD, 2000, p. 33-34). E por meio dos indivíduos dispostos a contar suas histórias e experiências, é possível conhecer e captar informações que podem ser transformadas em conhecimento científico.

Além dos relatos orais da professora Marilda, utilizamos documentos visuais, tal como fotos de sua prática docente com intuito de evidenciar alguns momentos de sua trajetória. Para chegar até a nossa fonte principal de pesquisa, a professora Marilda, seguimos por vários caminhos, os quais consideramos como as redes interdependentes e de sociabilidades que Marilda pertenceu e/ou passou ao longo da carreira.

Deste modo, começamos buscar informações sobre professoras aposentadas na secretaria da Igreja Católica da cidade, passamos pela escola estadual Juracy Alves Cardoso, onde Marilda trabalhou, na sequência visitamos uma de suas amigas de trajetória, e por fim chegamos à professora Marilda. Após esse processo fizemos duas visitas, a fim de nos aproximarmos mais da entrevistada e na terceira visita já gravamos a entrevista.

O momento da entrevista foi repleto de recordações e retomada de vivências da trajetória. Marilda parece ter voltado ao tempo e trazido à tona a sua vida, sua história bem como as experiências de sua carreira profissional. "A informação retida consiste em todo o nosso conhecimento do mundo e define à nossa maneira de ser: "Sou o que recordo" (BEN-PERETS, 2000, p. 212). Quando procuramos trazer os acontecimentos do passado para o presente a memória enfatiza aquilo que marcou a vida de alguma forma, e contamos o que lembramos com análise e olhos de hoje, e não com os do passado, porque vivemos o agora, e ontem já se foi.

As lembranças relatadas por Marilda nos informam o papel da memória como agente importante na compreensão de vivências e acontecimentos durante sua carreira docente, pois "[...] a memória do trabalho é o sentido, é a 
justificação de toda uma biografia" (BOSI, 1994, p. 481). Tais marcas da vida de uma pessoa ficam evidentes no momento em que ela está relatando sua história e a memória pode ser vista como "[...] propriedade de conservar certas informações [...] atualizar impressões ou informações passadas, ou que ele representa como passadas" (LE GOFF, 1990, p. 36). Ou seja, destacamos o lugar da memória no estudo das trajetórias de vida de professores, percebendo que a finalidade da memória não deve estar somente no "[...] dever de rememorar, mas também como dever de transmitir uma experiência indizível, a fim de impedir que se perca esse acontecimento único" (JOUTARD, 2006, p. 48).

\section{História de vida e os percalços da escolha da profissão}

A professora Marilda Ruiz Moralles Rodrigues é casada com o professor Mauro Cezar do Carmo Rodrigues, também aposentado, o casal tem três filhos e cinco netos. Marilda é filha de estrangeiros, nascida na capital paulista, onde viveu toda a sua infância, adolescência e juventude. Atualmente com 70 anos, reside em Naviraí/MS. Ela comenta que sua infância foi "[...] em Prudente, uma infância normal, família bem estruturada graças a Deus. Estudei tudo em colégio público" (Marilda, 2018). A professora relatou que iniciou sua vida escolar aos 07 anos no ensino primário e concluiu a escola normal magistério, em 1969 na cidade de Presidente Pudente/SP. Em 1976 Marilda veio visitar a família de seu esposo que residia em Naviraí/MS, e desse passeio surgiu a oportunidade de virem morar nesse município também. Ela relata:

Eu vim em julho de 1976 passear, meu sogro era advogado aqui, Dr. Castilho, nós viemos conhecer e passear. E nesse passeio eu conheci a diretora do Juracy, a Cleuza Campos numa festa. Ela tinha acabado de ficar sem a pedagoga em julho. Então perguntou se a gente não gostaria de vir para cá. Morava em Prudente eu dava aula lá, meu esposo também [...], minha família é todinha de lá. A Cleuza disse se eu não gostaria de vir para cá. E meu esposo por causa dos pais, achou interessante para ficar perto, então viemos. No dia 10 de julho já fui para lá só para fazer a mudança. Dia 10 de agosto eu já estava aqui no colégio Juracy Alves Cardoso dando aula (MARILDA, 2018).

Para Marilda a figuração familiar foi propicia para sua mudança do estado de São Paulo para Naviraí local onde constituiu toda a sua carreira docente. Deste modo, "[...] os seres humanos, em virtude de sua interdependência fundamental uns dos outros, agrupam-se sempre na forma de figurações específicas" Elias (2006, p. 26), e assim as relações interdependentes e de poder vão norteando o caminho e as escolhas que os indivíduos vão fazendo ao longo de suas vidas.

Nessa perspectiva, em relação à escolha da profissão, ouvimos duas versões de Marilda, porém a última foi validada pela própria depoente. $\mathrm{Na}$ primeira versão declarou que o que a levou ser professora foi seu próprio desejo, não teve influência de ninguém, disse que sempre lidava com crianças cuidando 
dos sobrinhos e gostava disso, "eu sempre gostei muito de lidar com criança" (MARILDA, 2018). Entretanto, no desenrolar da conversa durante a entrevista foi se estabelecendo uma aproximação maior com a depoente e percebemos que Marilda se sentiu mais à vontade e confiante para contar os detalhes de sua história, revelando-nos o que de fato influenciou na escolha de sua profissão, ou o real motivo que determinou a sua decisão pela docência, visto que ela não o fez porque queria, mas por uma imposição dos pais. Assim, Marilda conta com mais tranquilidade como se tornou professora de crianças:

Na realidade mesmo, Pedagogia foi a minha última opção. Eu queria fazer medicina. Meus pais [...] não permitiram que eu fosse estudar fora, e em Prudente não tinha Pedagogia. Então, eu fiz a segunda opção que foi Psicologia. [...]. Também não tinha em Prudente naquela época, tinha em Assis. Assis era bem menor que Prudente, mas tinha na época. Só que tinha que morar lá. Eu era a caçula, as duas irmãs mais velhas eram até casadas já, ele não deixou também de jeito nenhum. Falei então não vou fazer nada! Que eram as duas coisas que eu queria e não pude fazer (MARILDA, 2018).

Essa fase da vida de Marilda foi um período consolidado pela relação de poder entre a família, especificamente em relação ao pai, pois ela dependia da autorização dele para sair de casa e ir morar em outro lugar para estudar, mas não foi possível porque seu pai não acreditou ser boa ideia deixar uma menina morar longe da família, então Marilda obedeceu. Desta forma, vemos que,

[...] nas relações entre pais e filhos [...], as oportunidades de poder são distribuídas muito desigualmente. Porém, sejam grandes ou pequenas as diferenças de poder, o equilíbrio de poder está sempre presente onde quer que haja uma interdependência funcional entre pessoas. [...]. O poder não é um amuleto que um indivíduo possua e outro não; é uma característica estrutural das relações humanas - de todas as relações (ELIAS, 2005, p. 81).

Diante de tais circunstâncias Marilda foi se aproximando da formação para a docência, seguindo a ordem de seu pai como enfatizou:

Meu pai falou: "Você vai fazer o que a Mari vai fazer", que era minha sobrinha, ela vai ficar com você. Quer dizer, a sobrinha que ia cuidar da tia, ao invés da tia cuidar da sobrinha (risos). Foi quando ela foi fazer a tal da Pedagogia. Eu fui também, mas fui chorando para o vestibular. Eu não queria! Eu tinha acabado de sair do magistério estava tudo bem fresquinho. Eu fui à única que passou, a Mari e as outras primas reprovaram. No fim das contas fui fazer sozinha do mesmo jeito (MARILDA, 2018, grifo nosso).

Para a professora Marilda a escolha da profissão não foi algo desejado inicialmente, ou seja, um processo não pensado por ela, ou como diria Elias (2006, p. 37) "trata-se, [...] de um caminhar não-planejado", sendo um aspecto 
inevitável e circunstanciado pelas questões sociais e materiais no qual o indivíduo se encontra e não tem o poder de decisão em determinadas situações e acaba cedendo às ordens impostas a ele, vivenciando então o que Elias (1993) vai chamar de "processo cego".

Para o autor não há uma ordem ou sequência linear a ser seguida, as ações humanas estão postas ao acaso e são insertas. E com o tempo as pessoas mudam seus pensamentos e ações conforme a convivência no seio das redes sociais interdependentes que pertencem, e também a partir das mudanças socias e econômicas que acontecem num processo de longa duração que não tem fim. Segundo os estudos de Montiel (2019) e Faria (2018), que trataram sobre trajetórias docentes, aprendemos que na maioria das vezes as decisões tomadas acerca da escolha da profissão são influenciadas pela figuração familiar.

Interessante notar que depois de toda uma carreira construída e findada muitos desses professores, que não escolheram estar na docência, declararam ter seguido o caminho certo e passaram a gostar do que faziam. Muitas indagações surgem quando ouvimos professores afirmarem que durante a trajetória docente tudo pareceu se encaixar mesmo não tendo um início definido por eles. Será que realmente passaram a gostar de seu trabalho ou se viram na incapacidade de mudar de profissão, por falta de atitude, coragem, conhecimento ou comodismo? Ou realmente os anos de prática fizeram com que vissem a docência com outros olhos, amadureceram e sentiram o senso de pertencimento, como se aqui é meu lugar, aqui eu vou ficar?

Neste sentido, no caso de Marilda, a mesma destacou que durante sua formação já começou a se identificar com a que seria sua futura profissão colocando que "[...] lá dentro como eu já queria fazer Psicologia fui me encontrando. Os conteúdos eram pesados, tinha bastante livro para ler e resumir. Tinha estágios. Eu sempre gostei muito de criança, então casou tudo aí" (MARILDA, 2018). Marilda finalizou o curso de magistério em 1969 e já foi dar aula. Um ano depois começou o curso de Pedagogia finalizando em 1974, em Assis/SP. Após a Pedagogia Marilda participou de vários cursos de curta duração e cursos de pós-graduação como Supervisão Escolar, Administração escolar e Orientação escolar.

Fiz curso de pós-graduação e bastante cursinhos, atualizações que eles mandavam a gente fazer, pediam, incentivavam a gente não perdia nenhum. Lá para dar aula tinha que ter pontos. Então você terminava a Escola Normal com a nota da média dos três anos. Essa era a primeira nota. Começava a fazer os cursinhos, cada cursinho valia 1,0 ponto. Dependendo da pontuação pegava escola mais perto, mais longe, no centro ou nos bairros. Com a faculdade ganhava mais pontos ainda (MARILDA, 2018).

De acordo com Elias (2006), consideramos que para se tornarem profissionais, os indivíduos/professores necessitam de certas bases de conhecimentos e informações. Uma dessas bases centra-se os conhecimentos científicos dentro da área de atuação. Outra envolve os conhecimentos da 
profissão e os instrumentos para que ocorra a construção, do saber e a do fazer. O professor, durante a sua formação acadêmica, dispõe de uma diversidade de conhecimentos teóricos e práticos que o levam à construção de uma base para a atuação no seu campo de trabalho. E à medida que coloca em prática seus conhecimentos, fazendo, testando, vai construindo novas aprendizagens, tornando-se cada vez mais perito no que faz, constituindo-se assim autor de sua profissão. Por outro lado, vemos também uma exigência da profissão no sentido de manter os profissionais no processo de crescimento, cada vez mais, para que consigam ingressar e se manter na docência.

Contudo, entender a maneira como cada professor se forma e/ou formou significa situar as relações dentro das pluralidades que perpassam a vida, pois não existe formação no vazio. O processo formativo concebe troca de experiência, convívios sociais, bem como, conhecimentos e inúmeras interações. E "ter acesso ao modo como cada pessoa se forma é ter em conta a singularidade de sua história e sobretudo o modo singular como age, reage e interage com os seus contextos" (MOITA, 2000, p. 115). Desta forma, buscamos conhecer as reminiscências das interações e constituições da professora Marilda ao longo de sua trajetória docente, aspectos estes retratados a seguir.

\section{Memórias da docência}

O ingresso da professora Marilda na docência se deu em 1969, na cidade de Presidente Prudente/SP, em turmas de $1^{a}$ a $4^{a}$ série do primeiro grau nomenclatura usada à época - sendo que atuou até 1976. No mesmo ano de 1976 Marilda, juntamente com sua família, mudou-se para Naviraí/MS, local onde exerceu toda a sua carreira profissional. Em Naviraí/MS a professora seguiu a atividade docente com uma turma do curso do magistério da Escola Estadual Juracy Alves Cardoso, assim relata que "faz tanto tempo que nem consigo me lembrar direito, mas recordo que entrei ali para dar aula no magistério. Dei aula de Psicologia e de Filosofia" (MARILDA, 2018). Logo após, Marilda foi convidada também a assumir uma sala de turma de $2^{a}$ série, passando a trabalhar de manhã e à noite.

Posteriormente, iniciou seu trabalho com crianças de pré-escola. Isso, a partir da década de 1980, quando a secretaria de educação do estado de Mato Grosso do Sul ordenou que as escolas estaduais começassem a atender a demanda da pré-escola. Segundo Rodrigues (2019), até então a assistência social de cada município atendia as crianças de 0 a 6 anos por meio de programas e projetos sociais. De 1980 em diante a assistência social ficou responsável mais com a demanda de creche, e o estado seguiu atendendo a préescola com um caráter mais educacional. Em 1985 Marilda passou a trabalhar em duas turmas de pré-escola na mesma instituição estadual que ministrava aulas também no curso de magistério.

A foto a seguir é do acervo privado da Escola Estadual Juracy Alves Cardoso e representa uma das práticas desenvolvidas pela professora Marilda 
com as crianças da pré-escola, especificamente quando comemoraram o Dia das mães, no ano de 1989.

Figura 1: Comemoração ao dia das mães, 1989.

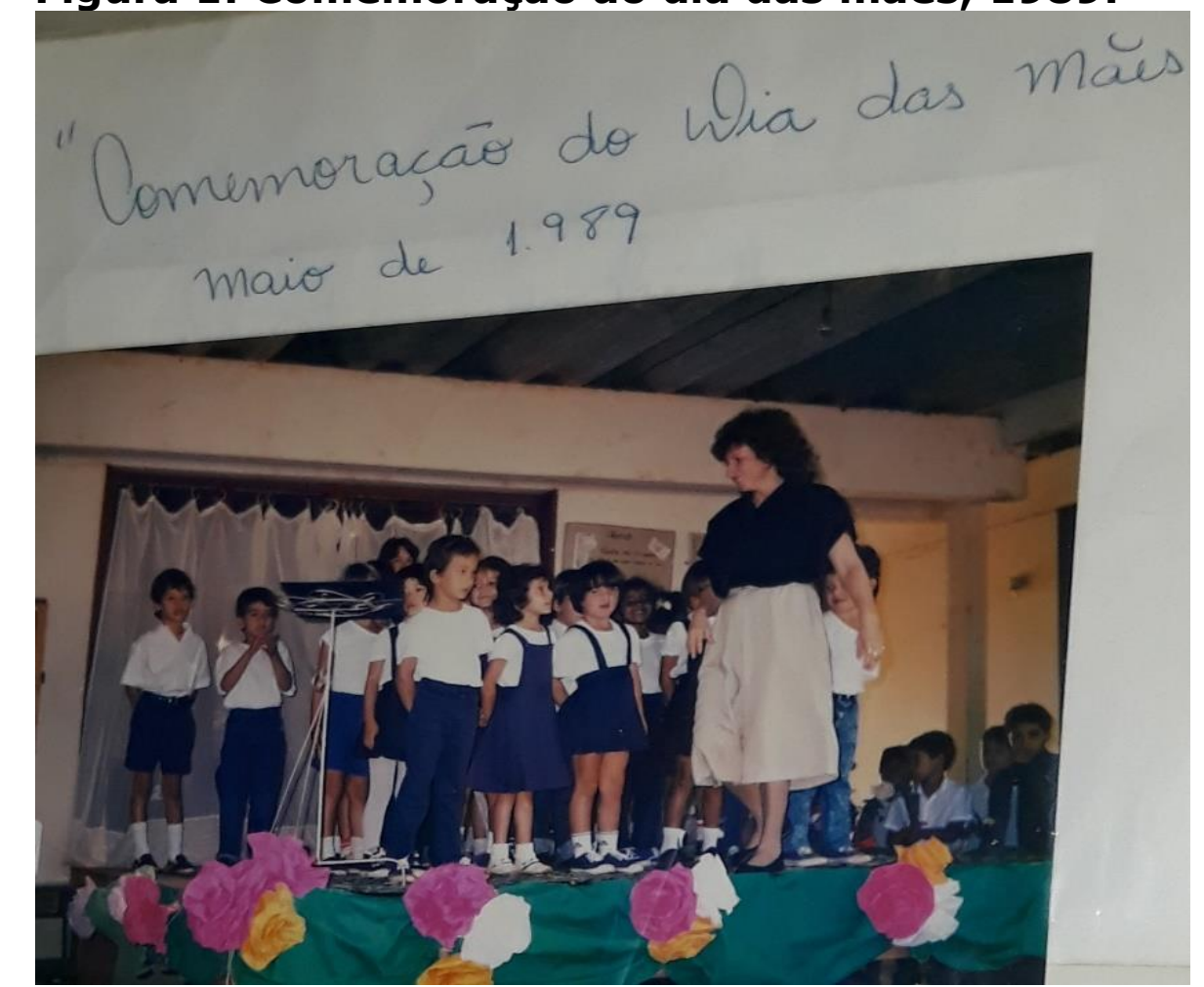

Fonte: Arquivo privado da Escola Estadual Juracy Alves Cardoso, 2018.

De acordo com o que a professora Marilda recordou ao olhar a figura 1 , também depreendemos da mesma forma, que as crianças estão no palco para se apresentarem para as mães e toda a escola. Era um dia de festa especial para as crianças e Marilda estava responsável pela organização do evento destinado às mães. Ela era regente do coral infantil e na foto organiza as crianças para começar a apresentação. Com base em Nora (1993), acreditamos que as datas comemorativas e rituais são lugares de memória que permitem o cruzamento entre o passado, o presente e o futuro: "[...] são marcos, testemunhos de uma outra era" (NORA, 1993, p. 13).

As datas comemorativas são abordagens que têm marcado o trabalho com as crianças pequenas ao longo da história do atendimento infantil. Foi a partir de 1996 com o surgimento da Lei de Diretrizes e Bases da Educação Nacional/LDB n 9.394/96, que trouxe novos caminhos para toda a educação básica, incluindo o reconhecimento da educação infantil como primeira etapa da educação, destacando também discussões sobre as práticas para trabalhar com as crianças da educação infantil (BRASIL, 1996). Daí em diante foram se desenvolvendo novas diretrizes, políticas, planos e programas que têm resultado em um novo olhar sobre a criança e seu atendimento propagado hoje (NUNES; CORSINO; DIDONET, 2011). 
Deste modo, Marilda relata como era organizada a sua sala de aula da turma da pré-escola:

Eram seis mesinhas, quatro cadeirinhas. Eram 24 de manhã e 24 à tarde. Os armários, a Cleuza era maravilhosa! Para ter minha sala expliquei para ela que as crianças eram muito pequenininhas não podiam ter o mesmo banheiro que os grandes. Então ela construiu uma sala com um banheirinho dentro com pia pequenininha para eles escovarem os dentes, depois do lanche. Era tudo bem bonitinho mesmo. Parecia uma casa de boneca (risos). Tudo enfeitado e decorado. Mandamos pintar as paredes com desenhos de temas infantis. A minha sala era a única suíte da escola com banheirinho pequenininho! (risos) (MARILDA, 2018, grifo nosso).

Na fala da professora Marilda percebemos que existia todo um cuidado em organizar o espaço para atender bem as crianças, por outro lado, nos chamou a atenção a forma como ela se referiu aos objetos e estrutura de sua sala infantil, utilizando o sufixo inho nas palavras, levando-nos a pensar na analogia equivocada, de que, se estamos lidando com crianças pequenas temos que conduzir a comunicação no diminutivo, por que é um ato respeitoso. Que mal tem de tratá-las assim? Na verdade, "[...] isso significa dizer que o sufixo inho e suas formas variantes, quando acrescidos a terminadas palavras, podem expressar diferentes sensações, emoções, desejos, pensamentos, intenções e assim por diante" (SILVA; LEBLER, 2020, p. 102). Deste modo, temos que estar cientes do que queremos transmitir ao fazermos o uso de sufixos diminutivos na comunicação com as crianças.

Os clássicos como Vygotsky (1985), Piaget (1986) e a bibliografia atual como Ostetto (2011), Barbosa (2000) e outros nos ajudam a pensar nessas questões, e se pararmos para refletir sobre como as crianças constroem conhecimento, pensamento e linguagem precisamos nos comunicar de maneira adequada, obedecendo às regras básicas da linguagem, favorecendo 0 desenvolvimento de habilidades psíquicas e linguísticas delas.

A sala de pré-escola na instituição que Marilda trabalhava era disputada por ser a única da escola e, para conseguir vaga, "[...] as mães posavam na frente do colégio. Outras chegavam $4 \mathrm{~h}, 5 \mathrm{~h}$ da manhã para conseguir. Porque encerradas as 24 vagas não tinha jeito de por mais ninguém, então encerrou, encerrou" (MARILDA, 2018). Outras instituições também ofereciam a pré-escola, mas existia uma demanda grande para atender, e as crianças que ficavam sem vagas nas escolas estaduais, passavam para a responsabilidade da assistência social do município.

Esse dilema seguiu até surgirem as mudanças na legislação nacional, propostas pela LDB no 9.394/96, citada anteriormente (BRASIL, 1996). A responsabilidade da educação infantil passou da assistência social para o setor educacional, a cargo dos municípios e não mais do estado. Contudo, esse foi um processo lento em todo o estado, em Naviraí tal prática foi efetivada em 2006, por meio de discussões e reuniões realizadas em Campo Grande entre a 
Secretaria Estadual de Educação do Estado e as Secretárias Municipais de Educação (MONTIEL, 2019).

Nesta direção, é possível afirmar que Marilda atuou nesses moldes e sua trajetória é fruto de todo esse processo de transformações ocorridas na educação de Naviraí/MS. A foto a seguir nos ajuda a interpretar um pouco mais o trabalho da professora.

\section{Figura 2: Encerramento do ano letivo, 1992.}

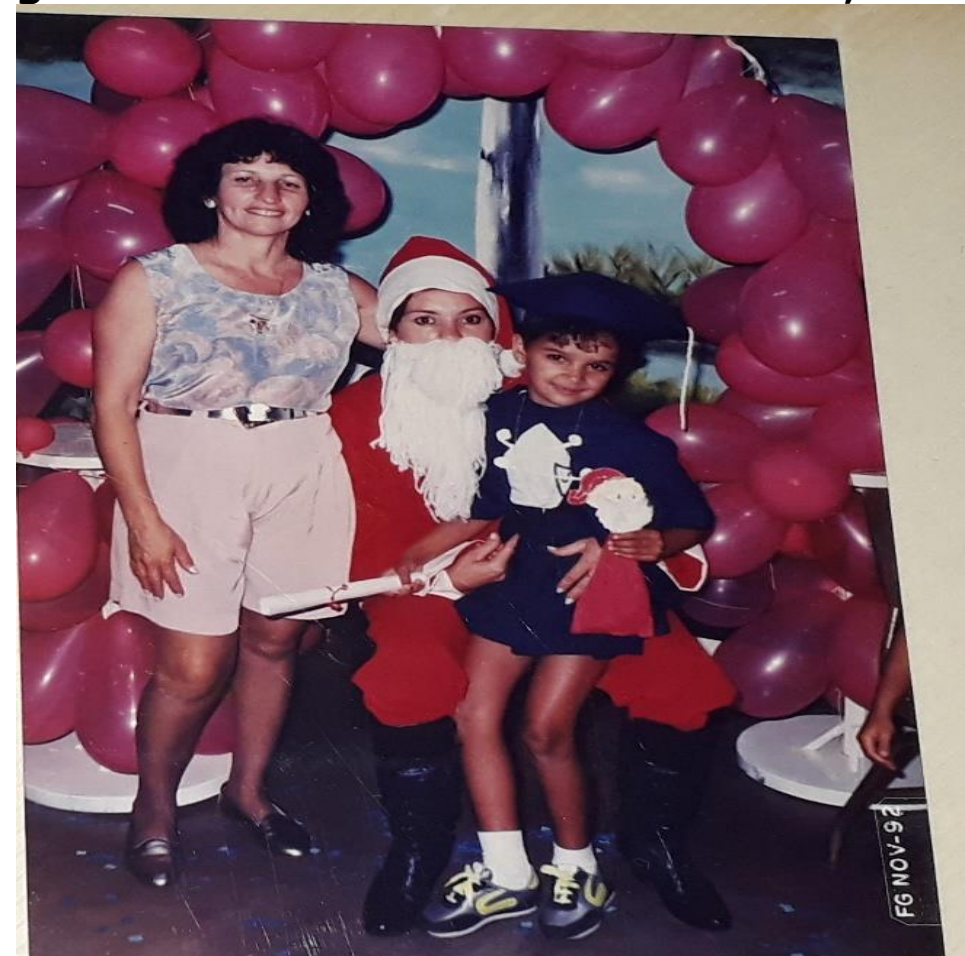

Fonte: Arquivo privado da Escola Estadual Juracy Alves Cardoso, 2018.

Essa foto refere-se ao enceramento do ano letivo de 1992 e mostra a professora Marilda à esquerda, ao lado da mamãe noel, com uma criança da turma pré-escolar no colo. Era costume da escola fazer formatura das crianças do pré-escolar junto com a comemoração de natal, como é nítido na foto a criança segurando o seu diploma de formatura nas mãos. Marilda destacou que tanto as crianças, como as famílias gostavam dessas celebrações que se tornaram algo cultural para todos. Nesse sentido, as imagens "[...] nos contam histórias (fatos/acontecimentos), atualizam memórias, inventam vivências, imaginam a História" (MAUAD, 2005, p. 135).

Assim, pensando no modelo do trabalho que Marilda realizava, principalmente referente às datas comemorativas, podemos dizer que as crianças, enquanto indivíduos em processo de aprendizagem, vão sendo conduzidas a receber uma "modelagem social" que vai tornando-as civilizadas, a partir de costumes, regras, normas, comportamentos, ritos e de modelos estabelecidos pelo seu grupo social desde a infância até tornarem-se adultos. A explicação dessa modelagem é que a criança/indivíduo cresce "[...] partindo de uma rede que existia antes dele para uma rede que ele ajuda a formar" (ELIAS, 
1994, p. 30). Contudo, esses momentos formam padrões sociais que serão convenientes e importantes na sociabilidade para as crianças individual e coletivamente no desenvolvimento de suas vidas.

Nesta perspectiva, Marilda disse mais acerca de sua experiência, dando ênfase a sua prática com as crianças e os recursos que usava para trabalhar. "As crianças tinham uniforme bonitinho. A diretora dava uma lista de materiais para os pais comprar. Compravam livrinhos de historinha, lápis de cor, giz de cera, papel crepom o que pudesse doar era bem-vindo" (MARILDA, 2018). Segundo a professora, a escola tinha a Associação de Pais e Metres/APM que ajudava quem não tinham condições de comprar material porque a secretaria do estado de educação nem sempre mandava o suficiente. Marilda priorizava o lúdico nas atividades com as crianças conforme narrou:

Tinha os paninhos das bonecas, eu levava sabão de casa e a gente fazia o tanquinho. Era o dia de lavar as roupas das bonecas. E os meninos faziam os varais e ajudavam. Fazíamos piquenique, brincávamos de guerra, subíamos nas árvores, tinha de tudo. Tinha dia que eles iam embora parecendo uns tatuzinhos de tão sujos porque íamos na terra e fazíamos a festa. Aprendiam brincando. Eles adoravam (MARILDA, 2018).

Assim, a forma pela qual cada professor ensina está diretamente ligada à forma que é, enquanto pessoa quando exerce seu trabalho. E esse ser é moldado de acordo com as figurações a que pertence e às relações interdependentes compartilhadas, permitindo reconhecer também que essa experiência de si é fruto de um resultado, de um devir, o qual faz parte de um processo social (ELIAS, 2001). Todo o funcionamento da vida social dos indivíduos/professores "[...] é influenciado pela natureza da visão consciente que eles têm disso, pelo que pensam e pela maneira como pensam" (ELIAS, 2001, p. 119).

A constituição do ser professor resulta das diferentes relações nas quais ele está imerso, pois todas as pessoas envolvidas no ambiente escolar (professores, pais, gestores, ministros, alunos etc.) modelam suas ideias por meio das suas experiências sociais e de vida. Nóvoa corrobora essa questão quando coloca que "[...] as opções que cada um de nós tem de fazer como professor, as quais cruzam à nossa maneira de ser com a nossa maneira de ensinar e desvendam na nossa maneira de ensinar à nossa maneira de ser" (2007, p. 17). Ou seja, está tudo interligado, o ser e o fazer docente. Isso ficou evidente para nós conforme fomos dialogando com Marilda e verificando a relação que fazia sobre as suas percepções pessoais, visão de mundo e o seu trabalho. Como podemos ver em seu relato ao dizer sobre o teatro infantil que ajudou a formar na escola:

Fizemos um coral com eles e na formatura cantavam umas 5, 6 musiquinhas. Era o coral do Juracy. Nós fomos à Campo Grande, lá tinha um teatro bem famoso que tinha festivais naquela época, de corais infantis. E o nosso sempre ia. Fazíamos a inscrição, as 
mães iam junto à diretora, era uma molecada toda uniformizada, bonitinha com roupa de coral mesmo, cantávamos lá, nos divertíamos muito. Até ganhamos prêmio uma vez (MARILDA, 2018).

O teatro famoso de Campo Grande que a professora menciona em sua fala é o chamado Glauce Rocha que existe até hoje. Ele foi criando dentro da Universidade Estadual de Mato Grosso - UEMT em 1971 e leva o nome Glauce Rocha em homenagem a uma atriz campo-grandense que morreu nesse mesmo ano. Atualmente é ligado à Universidade Federal de Mato Grosso do Sul - UFMS e é considerado um dos maiores espaços para atrações artísticas do estado (YOKOYAMA, 2018).

A foto abaixo mostra um trecho do Jornal Correio do Sul, destacando a participação do coral da turma do pré-escolar da professora Marilda no primeiro Encontro de Coros Sul-mato-grossense promovido pela UFMS.

Figura 3: Coral Do-ré-mi no $1^{\circ}$ encontro Sul-Mato-Grossense de Coros, sem data.

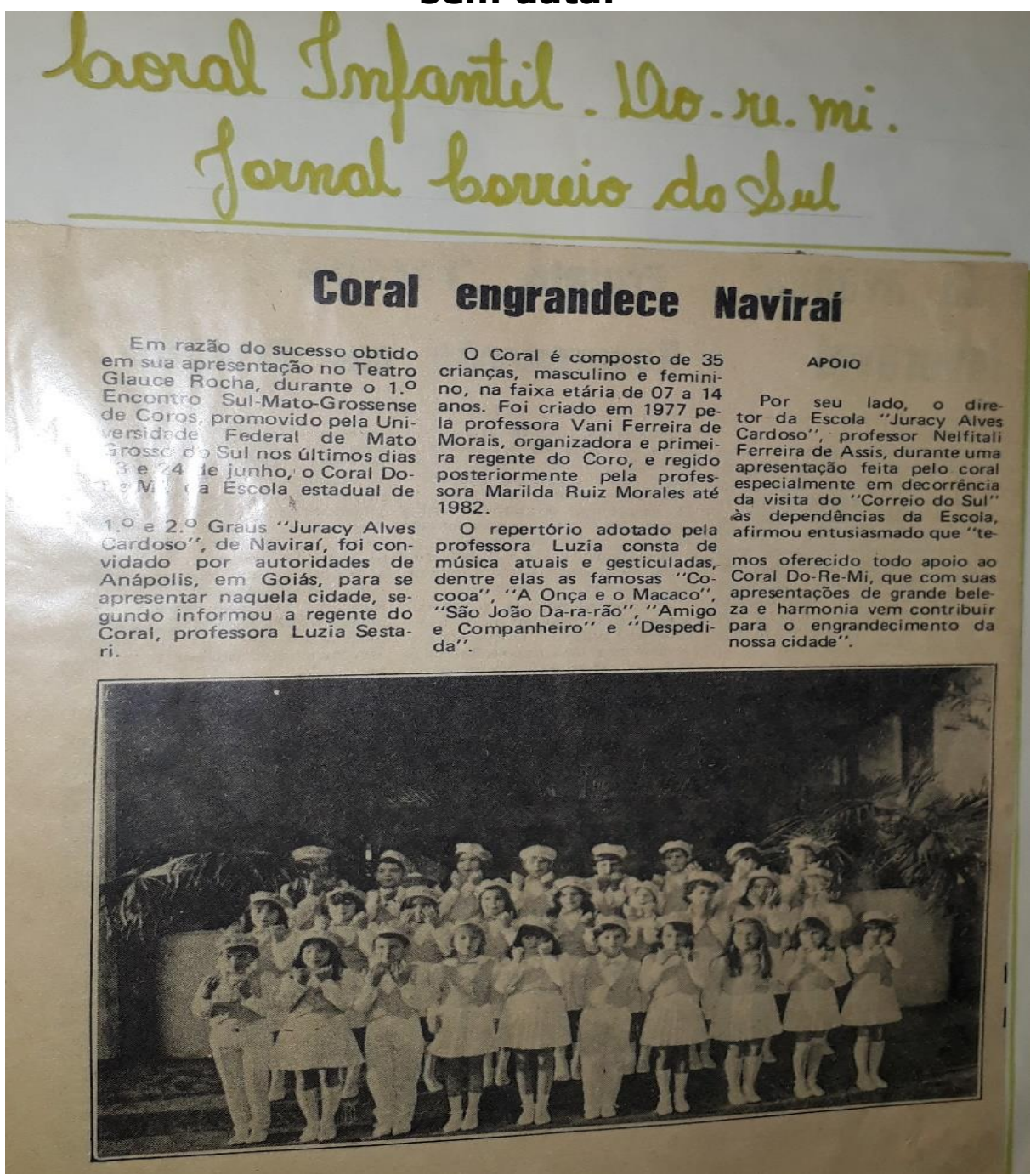

Fonte: Arquivo privado da Escola Estadual Juracy Alves Cardoso, 2018. 
Não conseguimos saber ao certo a data desse evento, mas segundo as pistas das fontes fotográficas a que tivemos acesso, acreditamos ter ocorrido no fim da década de 1970 e início de 1980. Deste modo, segundo Sarat (2004), quando o indivíduo/professor narra os acontecimentos de sua vida ele recorda aquilo que marcou significativamente sua carreira, selecionando por meio da memória desvalorizando ou valorizando fatos passados com o olhar de hoje. E assim "[...] como o reflexo de um processo de cristalização das suas teorias e convicções pedagógicas, associando-as explicitamente a determinadas experiências e ocorrências da sua prática" (PERETS, 2000, p. 211), e foi o que Marilda fez ao trazer para o tempo presente momentos muito particulares de sua trajetória.

A professora também enfatizou a dificuldade que os professores têm hoje para trabalhar com crianças, alegando que as mesmas são mais agitadas, questionadoras demais, malcriadas e ninguém está dando conta direito, nem família nem escola.

Naquela época era diferente. As crianças não tinham negócio de celular, não tinha nada disso. Eu trabalhava com brincadeiras, ativava a imaginação delas. E tudo que o professor falava naquela época era lei. Engraçado elas acreditavam na gente. Está tudo diferente hoje. A professora vai falar alguma coisa o aluno já fala "Credo tia, isso não existe não, não é assim não!" ou se chama atenção dele, chega em casa e os pais vêm na escola brigar com o professor. Na minha época o professor era mais respeitado. Se eu brigava com o moleque, ele chegava em casa ia reclamar e os pais falavam: se ela brigou foi porque você mereceu, obedece a sua professora. Acho que me aposentei no tempo certo (MARILDA, 2018).

A professora Marilda teve uma experiência de 38 anos na profissão docente, a qual passou pela sala de aula, direção e supervisão pedagógica no decorrer de sua trajetória. E o maior tempo de sua atuação foi na sala de aula em turmas da fase pré-escolar. A aposentadoria pelo estado findou no ano de 2000 e depois disso Marilda trabalhou em uma escola particular até 2007, quando definitivamente decidiu que era hora de descansar.

Eu já tinha dado mais de 30 anos de aula. Fui diretora e coordenadora também. Aposentei no estado em 2000 e fiquei só no particular, mas daí a gente vai vendo que está cansando, sabe? Pela diretora eu poderia ter ficado lá até hoje. Mas temos que dar oportunidade para outras pessoas. Então vai ficar um mausoléu lá (risos) andando já toda torta com dorzinha aqui, dorzinha ali e outras pessoas sem uma sala para dar aula? Tem que dar a vez para os outros também. Então vi que já tinha dado (MARILDA, 2018, grifo nosso).

Na fala de Marilda percebemos sua atitude civilizada e empática de pensar no próximo, dar a sua vez para o outro, já que a saúde também não oferece muitas condições mais. Achar que é hora de descansar significa dizer 
que o ciclo profissional chegou, ao fim, então essa é agora, a fase da serenidade de sossego, tranquilidade, paz e outros poderão ocupar o seu lugar (HUBERMAN, 2000).

Atualmente Marilda dedica seu tempo à família, esposo, filhos e netos. Também participa de grupos de oração em sua igreja e está sempre viajando "não paro aqui não. Viajo muito pelo Brasil todo e quando chego de uma viagem já programo outra. E atuo na igreja. Nós temos um grupo de oração" (MARILDA, 2018). Marilda teve uma carreira bem sucedida e dedicou toda a sua vida à docência, hoje se sente feliz e realizada, principalmente quando encontra seus pequenos alunos que são pessoas bem sucedidas tanto na vida familiar como na profissional.

\section{Considerações finais}

A discussão sobre a história de vida e memórias da docência da professora Marilda, realizada neste estudo, nos permitiu perceber que as relações estabelecidas nas redes de interdependências que os indivíduos passam ou pertencem ao longo da vida influenciam em suas escolhas pessoais e profissionais. E as experiências construídas durante a carreira docente vão sendo ampliadas, conforme as relações sociais constituídas e a própria percepção do indivíduo/professor, sobre ele mesmo, o mundo, o trabalho docente configurando assim, o seu jeito de ser e o seu jeito de fazer.

Deste modo, enfatizamos a importância da memória no estudo das histórias de vidas e trajetórias docentes pelo poder de atuar como uma caixa de surpresas, trazendo as lembranças e fatos marcantes que aconteceram no passado, e que agora, no tempo presente, o indivíduo pode reconstruir sua história, reviver sentimentos e até mesmo pensar em sua função social diante destas memórias narradas.

Nesta perspectiva, a história e as memórias da professora Marilda colaboraram com a escrita da História da Educação e possibilitaram discussões sobre a profissão, memórias e trajetórias docentes no interior de Mato Grosso do Sul, pois as pesquisas nessa localidade ainda são incipientes, o que evidencia a importância de ampliar as discussões e reflexões sobre a temática.

\section{REFERÊNCIAS}

BARBOSA, Maria. Carmen. Silveira. Por amor \& por força: rotinas na educação infantil. 2000. Tese (Doutorado) - Faculdade de Educação da UNICAMP, Campinas, SP. Disponível em: http:

//taurus.unicamp.br/bitstream/REPOSIP/253489/1/Barbosa_MariaCarmenSilve ira_D.pdf/. Acesso em: 28 jan. 2019. 
BEN-PERETS, M. VI II Episódios do passado evocados por professores aposentados. In: NÓVOA, A (Org.). Vidas de professores. $2^{\circ} \mathrm{Ed}$. Portugal: Porto Editora, 2000.

BOSI, Ecléia. Tempo de lembrar. In. (Org.). BOSI, Ecléia. Memória e sociedade: Lembranças de velhos. Companhia das letras, 3 ed. São Paulo, 1994.

BRASIL. Lei n 9.394, de 20 de dezembro de 1996. Estabelece as Diretrizes e Bases da Educação Nacional. Brasília: Senado Federal. Coordenação de Edições Técnicas, 2017, 58 p. Disponível em: http://www2.senado.leg.br/bdsf/bitstream/handle/id/529732/lei_de_diretri zes_e_bases_1ed.pdf/. Acesso em: 18 mar. 2018.

ELIAS, Norbert. Norbert Elias por ele mesmo. In: Zahar, Jorge. (Org.). Norbert Elias por ele mesmo. Tradução, TELLES, A. Rio de Janeiro: Ed., 2001.

ELIAS, Norbert. ; SCOTSON, John. L. Os estabelecidos e os outsiders: sociologia das relações de poder a partir de uma comunidade. Tradução de Vera Ribeiro. Tradução do posfácio de Pedro Sussekind. Apresentação e revisão técnica de Frederico Neiburg. Rio de Janeiro: Zahar, 2000.

FARIA, Horta. Adriana. Trajetórias de professores homens que atuaram com crianças no interior de Mato Grosso do Sul (1962-2007).

Dissertação (Mestrado em Educação) - Faculdade de Educação FAED Universidade Federal da Grande Dourados - UFGD. Dourados/MS, 2018.

HALBWACHS, Maurice. A memória coletiva. Tradução Laurent Léon Schaffter. São Paulo: Vértice Editora/Editora Revista dos Tribunais, 1990. p. 189.

HUNGER, Dogmar; ROSSI, Fernanda.; NETO, Souza. Samuel. A teoria de Norbert Elias: uma análise do ser professor. Educação e Pesquisa, São Paulo, v. 37, n. 4, p. 697-710, dez. 2011. Disponível em: https://www.scielo.br/pdf/ep/v37n4/a02v37n4.pdf/. Acesso em 18 de out. 2020.

HUBERMAN, Michael. O ciclo de vida profissional dos professores. In: NÓVOA, Antônio (org.) Vida de professores. 2a ed. Porto: Porto Editora, 2007, p. 3161.

JOUTARD, Philippe. Desafios à história oral do século XXI. In: MORAES, M. F.; FERNANDES, M. T. ; ALBERTI, V. (Orgs.) História oral: desafios para o século XXI. Rio de Janeiro: Editora Fiocruz/Casa de Oswaldo Cruz / CPDOC Fundação Getúlio Vargas, 2000, p. 31-45. 
LE GOFF, Jacques. História e memória. Tradução de Bernardo Leitão et al. Campinas, SP: Editora da UNICAMP, 1990 (Coleção Repertórios). Disponível em: https://www.ufrb.edu.br/ppg com/images/Hist\%C3\%B3ria-eMem\%C3\%B3ria.pdf/. Acesso em: 24 jun. 2018.

MOITA, Maria da. Conceição. Percursos de formação e de transformação. In: NÓVOA, A (Org.). Vidas de professores. $2^{\circ} \mathrm{Ed}$. Portugal: Porto Editora, 2000.

MONTIEL, Larissa. Wayhs. Trein. A tessitura do direito à educação em Mato Grosso do Sul: um estudo da trajetória do Plano Estadual de Educação (1983-2003). Dissertação (Mestrado em Educação) - Faculdade de Educação. Universidade Federal da Grande Dourados - UFGD, Dourados/MS, 2010, 257p.

NÓVOA, Antonio. Os professores e as histórias da sua vida. In: Nóvoa, Antonio, (org.). Vidas de professores. 2 ed. Porto, PT: Porto, 2007. p. 1130.

NORA, Pierre. Entre memória e história: a problemática dos lugares.

Tradução: Yara Aun, Khoury. Projeto História. PUC - SP 10 de dezembro, 1993. NUNES, Maria. Fernandes. Rezende.; CORSINO, Patrícia.; DICONET, Vidal.

Educação infantil no Brasil: primeira etapa da educação básica. Brasília, DF: UNESCO, Ministério da Educação. Secretaria de Educação Básica, Fundação Orsa, 2011.

OSTETTO, Esmeralda. Luciana. Educação Infantil e Arte: Sentidos e Práticas Possíveis. Objetos educacionais, UNESP. Acervo digital, 2011. Disponível em: https://acervodigital.unesp.br/bitstream/123456789/320/1/01d14t01.pdf/. Acesso em 16 de ago. de 2020.

RODRIGUES, Giseli. Tavares. Souza. História do Clube de Mães e as origens do atendimento à criança pequena em Naviraí/MS (1974 - 1990). Dissertação (Mestrado em Educação) - Faculdade de Educação. Universidade Federal da Grande Dourados - UFGD, Dourados/MS, 2019, 172p.

SARAT, Magda. Histórias de estrangeiros no Brasil: infância, memória e educação. 2004. Tese (Doutorado em Educação). Universidade Metodista de Piracicaba - Unimep, Piracicaba/SP.

SILVA, Soares. Fabiana.; LEBLER, Cortivo'Dall. Cristiane. O uso do diminutivo inho e suas possíveis significações pelo viés da Teoria dos Blocos Semânticos (TBS) e da Linguística Formal. Signo. Santa Cruz do Sul, jan./abr. 2020, v.45, n. 82, p. 101-111. Disponível em: https://online.unisc.br/seer/index.php/signo/article/view/14265/pdf/. Acesso em: 19 fev. 2021. 
PIAGET, Jean. A linguagem e o pensamento da criança. São Paulo: Martins Fontes, 1986.

VYGOTSKY, Lev. Semyonovich. Pensamento e linguagem. São Paulo: Martins Fontes, 1985.

YOKOYAMA, Geovanna. Teatro Glauce Rocha é cenário histórico de grandes espetáculos de MS. 2018. Disponível em: https://www.ufms.br/teatro-glaucerocha-e-cenario-historico-de-grandes-espetaculos-do- ms/. Acesso em: 20 de fev. 2021.

\section{Entrevista :}

Marilda Ruiz Moralles Rodrigues. Trajetória Profissional e História da Educação Infantil. Entrevista concedida a Giseli Tavares de Souza Rodrigues. Naviraí/MS, em março de 2018.

Recebido em: 11 de março de 2021. Aceito em: 21 de junho de 2021. Publicado em: 30 de junho de 2021. 